\title{
Long Memory and Volatility Dynamics in the US Dollar Exchange Rate
}

\author{
Guglielmo Maria Caporale \\ Brunel University, UK \\ Luis A. Gil-Alana \\ University of Navarra, Spain
}

This paper focuses on nominal exchange rates, specifically the US dollar rate vis-à-vis the Euro and the Japanese Yen at a daily frequency. In the paper both absolute values of returns and squared returns are modelled using long-memory techniques, being particularly interested in volatility modelling and forecasting. Compared with previous studies using fractional integration such as Granger and Ding (1996), a more general model is estimated, which allows for dependence not only at the zero but also at other frequencies. The results show differences in the behaviour of the two series: a long-memory cyclical model and a standard I(1) model seem to be the most appropriate for the US dollar rate vis-à-vis the Euro and the Japanese Yen respectively. (JEL: $\mathrm{C} 22, \mathrm{O} 40)$

Keywords: Fractional integration, Long memory, Exchange rates, Volatility

\section{Introduction}

The empirical literature analysing the statistical properties of exchange rates is vast. Most studies focus on the behaviour of real exchange rates in order to establish whether it is consistent with the theory of Purchasing Power Parity (PPP), which is one of the central tenets of the theory of exchange rate determination. In particular, they test the null hypothesis that the real exchange rate follows a random walk, the

\footnotetext{
* Corresponding author: Professor Guglielmo Maria Caporale, Centre for Empirical Finance, Brunel University, West London, UB8 3PH, UK. Tel.: +44 (0)1895 266713. Fax: +44 (0)1895 269770. Email: Guglielmo-Maria.Caporale@brunel.ac.uk
}

(Multinational Finance Journal, 2012, vol. 16, no. 1/2, pp. 105-136)

(C) Multinational Finance Society, a nonprofit corporation. All rights reserved. DOI: $10.17578 / 16-1 / 2-5$ 
alternative being that PPP holds in the long run. However, such unit root tests are now well known to have very low power unless very long spans of data are used (see, e.g., Lothian and Taylor, 1996, and Cheung and Lai, 1994). Moreover, whilst in a flexible-price monetary model PPP is assumed to hold continuously, in a sticky-price model it holds only in the long run. Therefore the relevant issue to investigate is whether deviations from PPP are transitory or permanent.

As a result of the increasing awareness of the limitations of standard unit root tests as well as of possible frictions in foreign exchange markets, long-memory and fractional integration methods have been used much more frequently. For instance, applying R/S techniques to daily rates for the British pound, French franc and Deutsche mark, Booth et al. (1982) found positive memory during the flexible exchange rate period (1973-1979) but negative one (i.e., anti-persistence) during the fixed exchange rate period (1965-1971). Cheung (1993) also found evidence of long-memory behaviour in foreign exchange markets during the managed floating regime. On the other hand, the results obtained by Baum et al. (1999) estimating an ARFIMA model for real exchange rates in the post-Bretton Woods era do not support long-run PPP.

Other studies focus on the behaviour of nominal exchange rates. In this case, the main motivation is often building a model with better forecasting properties, rather than test theories of exchange rate determination, and in particular the financial modelling and forecasting of exchange rate volatility. This is because, from a dealer's perspective, what is of interest is not so much the ability to predict fluctuations in the exchange rate level, but rather in its volatility.

Some examples of recent studies analysing nominal exchange rate dynamics using fractional integration (looking at futures in particular) are those by Fang et al. (1994), Crato and Ray (2000) and Wang (2004). Volatility dynamics in foreign exchange rates (mainly the Deutsche mark vis-à-vis US dollar rate) have also been examined with the FIGARCH-model, introduced by Baillie et al. (1996), and subsequent papers using this approach are Andersen and Bollerslev (1997, 1998), Tse (1998 - examining the Japanese Yen-US dollar rate), Baillie et al. (2000), Kihc (2004) and Morana and Beltratti (2004 - analysing volatility).

The present study also focuses on nominal exchange rates, specifically the US dollar rate vis-à-vis the Euro and the Japanese Yen at a daily frequency. Both absolute values of returns and squared returns are modelled using long-memory techniques, being particularly 
interested in volatility modelling and forecasting. Compared with previous studies using fractional integration such as Granger and Ding (1996), a more general model is estimated which allows for dependence not only at the zero but also at other frequencies.

The layout of the paper is the following. Section II describes the methodology. Section III presents the empirical results. Section IV examines the stability of the relationships over time. Section V examines the forecasting properties of the estimated models, while Section VI offers some concluding remarks.

\section{Methodology}

Given a covariance stationary process $\left\{x_{t}, t=0, \pm 1, \ldots\right\}$, with autocovariance function $E\left[\left(x_{t}-E x_{t}\right)\left(x_{t-j}-E x_{t}\right)\right]=\gamma_{j}$, according to McLeod and Hipel (1978), $x_{t}$ displays the property of long memory if

$$
\lim _{T \rightarrow \infty} \sum_{j=-T}^{T}\left|\gamma_{j}\right|
$$

is infinite. An alternative definition, based on the frequency domain is as follows. Suppose that $x_{t}$ has an absolutely continuous spectral distribution, and therefore a spectral density function, denoted by $f(\lambda)$, and defined as

$$
f(\lambda)=\frac{1}{2 \pi} \sum_{j=-\infty}^{\infty} \gamma_{j} \cos \lambda j, \quad-\pi<\lambda \leq \pi
$$

Then, $x_{t}$ displays long memory if this function has a pole at some frequency $\lambda$ in the interval $[0, \pi]$. Most of the empirical literature has focused on the case when the singularity or pole in the spectrum occurs at the zero frequency. This is true in the standard fractionally integrated or $\mathrm{I}(d)$ models of the form:

$$
(1-L)^{d} x_{t}=u_{t}, \quad t=0, \pm 1, \ldots
$$

with $x_{t}=0, t \leq 0$, and where $L$ is the lag operator $\left(L x_{t}=x_{t-1}\right), d$ is a positive real value, and $u_{t}$ is an $\mathrm{I}(0)$ process defined as a covariance stationary process with a spectral density function that is positive and 
bounded at all frequencies. ${ }^{1}$ As previously mentioned these processes are characterised by a spectral density function which is unbounded at the zero frequency.

However, a process may also display a pole or singularity in the spectrum at a frequency away from zero. In this case, the process may still display the property of long memory but the autocorrelations exhibit a cyclical structure that is decaying very slowly. This is the case of the Gegenbauer processes defined as:

$$
\left(1-2 \cos w_{r} L+L^{2}\right)^{d} x_{t}=u_{t}, \quad t=1,2, \ldots
$$

where $w_{r}$ and $d$ are real values, and $u_{t}$ is $\mathrm{I}(0)$. For practical purposes we define $w_{r}=2 \pi r / T$, with $r=T / s$, and thus $s$ will indicate the number of time periods per cycle, while $r$ refers to the frequency that has a pole or singularity in the spectrum of $x_{t}$. Note that if $r=0$ (or $s=1$ ), the fractional polynomial in (2) becomes $(1-L)^{2 d}$, which is the polynomial associated with the common case of fractional integration at the long-run or zero frequency. This type of process was introduced by Andel (1986) and subsequently analysed by Gray et al. (1989, 1994), Giraitis and Leipus (1995), Chung (1996a,b) and Dalla and Hidalgo (2005) among many others.

Gray et al. $(1989,1994)$ showed that the polynomial in (2) can be expressed in terms of the Gegenbauer polynomial, such that, denoting $\mu=\cos w_{r}$, for all $d \neq 0$,

$$
\left(1-2 \mu L+L^{2}\right)^{-d}=\sum_{j=0}^{\infty} C_{j, d}(\mu) L^{j}
$$

where $C_{j, d}(\mu)$ are orthogonal Gegenbauer polynomial coefficients recursively defined as:

$$
\begin{gathered}
C_{0, d}(\mu)=1, \\
C_{1, d}(\mu)=2 \mu d,
\end{gathered}
$$

1. The $\mathrm{I}(0)$ class of models includes the classical white noise process but also other structures allowing a weak dependence structure, such as the stationary autoregressive moving average (ARMA) models. 


$$
C_{j, d}(\mu)=2 \mu\left(\frac{d-1}{j}+1\right) C_{j-1, d}(\mu)-\left(2 \frac{d-1}{j}+1\right) C_{j-2, d}(\mu), j=2,3, \ldots
$$

(see, for instance, Magnus et al., 1966, Rainville, 1960, etc. for further details on Gegenbauer polynomials). Gray et al. (1989) showed that $x_{t}$ in (2) is (covariance) stationary if $d<0.5$ for $\left|\mu=\cos w_{r}\right|<1$ and if $d<$ 0.25 for $|\mu|=1 .^{2}$ The model just presented can be generalised to the case of more than one cyclical structure to consider processes of the form:

$$
\prod_{j=1}^{k}\left(1-2 \cos w_{r}^{(j)} L+L^{2}\right)^{d_{j}} x_{t}=u_{t}, \quad t=1,2, \ldots
$$

where $k$ is a finite integer indicating the maximum number of cyclical structures, and $w_{r}^{(j)}=2 \pi / s_{(j)}$ where $s_{(j)}$ indicates the number of time periods per cycle corresponding to the $j^{\text {th }}$ cyclical structure. Empirical studies based on multiple cyclical structures of this type (also named $k$-factor Gegenbauer processes) are Ferrara and Guegan (2001), Sadek and Khotanzad (2004) and Gil-Alana (2007).

In this paper a flexible specification is adopted that allows us to analyse long-memory models of the form (1) and (2) in a single framework. Specifically, it is considered processes of the form:

$$
(1-L)^{d_{1}}\left(1-2 \cos w_{r} L+L^{2}\right)^{d_{2}} x_{t}=u_{t}, \quad t=1,2, \ldots
$$

where $u_{t}$ is again $\mathrm{I}(0), d_{1}$ indicates the order of integration at the long-run or zero frequency, and $d_{2}$ refers to the cyclical long-run dependence component.

A parametric approach developed by Robinson (1994) is employed that is very general in the sense that it allows to consider all the above specifications in a single framework. This method, based on the Whittle function in the frequency domain, has the advantage that it is valid for any real value $d$ (or $d_{1}$ and $d_{2}$ in (5)), thus encompassing stationary $(d<$ $0.5)$ and nonstationary $(d \geq 0.5)$ hypotheses. Moreover, the limiting distribution is standard (normal, in the cases of equations (1) and (2))

2. Note that if $|\mu|<1$ and $d$ in (2) increases beyond 0.5 , the process becomes "more nonstationary" in the sense, for example, that the variance of the partial sums increases in magnitude. 
TABLE 1. Descriptive statistics

\begin{tabular}{|c|c|c|c|c|}
\hline Series & Mean & Std. Deviation & Minimum & Maximum \\
\hline US - Euro & 1.17045 & 0.19554 & 0.82716 & 1.60100 \\
\hline US - Yen & 112.63360 & 8.96991 & 87.843 & 134.776 \\
\hline Rtn: US - Euro & 0.0000779 & 0.006506 & -0.030031 & 0.04620 \\
\hline Rtn: US - Yen & -0.0000828 & 0.006871 & -0.052156 & 0.0323608 \\
\hline
\end{tabular}

and chi-square in the case of (5)), and this standard limit behaviour holds independently of the inclusion or exclusion of deterministic terms in the model and the modelling approach for the $\mathrm{I}(0)$ disturbances. Moreover, Gaussianity is not a requirement, a moment condition of only 2 being necessary.

\section{Empirical results}

The time series data examined are the US foreign exchange rates with respect to the Euro and the Japanese Yen, daily, for the time period January $4^{\text {rd }}, 1999$ - October $2^{\text {nd }}, 2009$. These data were obtained from the Federal Reserve Bank of St. Louis database (DEXUSEU and DEXJPUS for the US-Euro and US-Yen rates respectively). Some descriptive statistics for the two variables are reported in table 1.

Plots of the two series are displayed in the upper half of figure 1, while their corresponding returns, obtained as the first differences of the logged values, are shown in the bottom half. First, the order of integration of the log-series is estimated to determine if they contain unit roots. For this purpose, initially standard unit root tests (Dickey and Fuller, ADF, 1979; Phillips and Perron, PP, 1988; Elliot et al., 1996; and $\mathrm{Ng}$ and Perron, NP, 2001) were carried out, finding evidence of unit roots (the results are not reported for brevity's sake) in the two series. However, it is well known that these procedures may have very low power if the true data generating processes are fractionally integrated. Therefore, other tests were also performed that, unlike the above, are not based on autoregressive alternatives but on fractional ones. In particular, it is considered a regression model of the form:

$$
y_{t}=\alpha+\beta t+x_{t} ; \quad t=1,2, \ldots,
$$




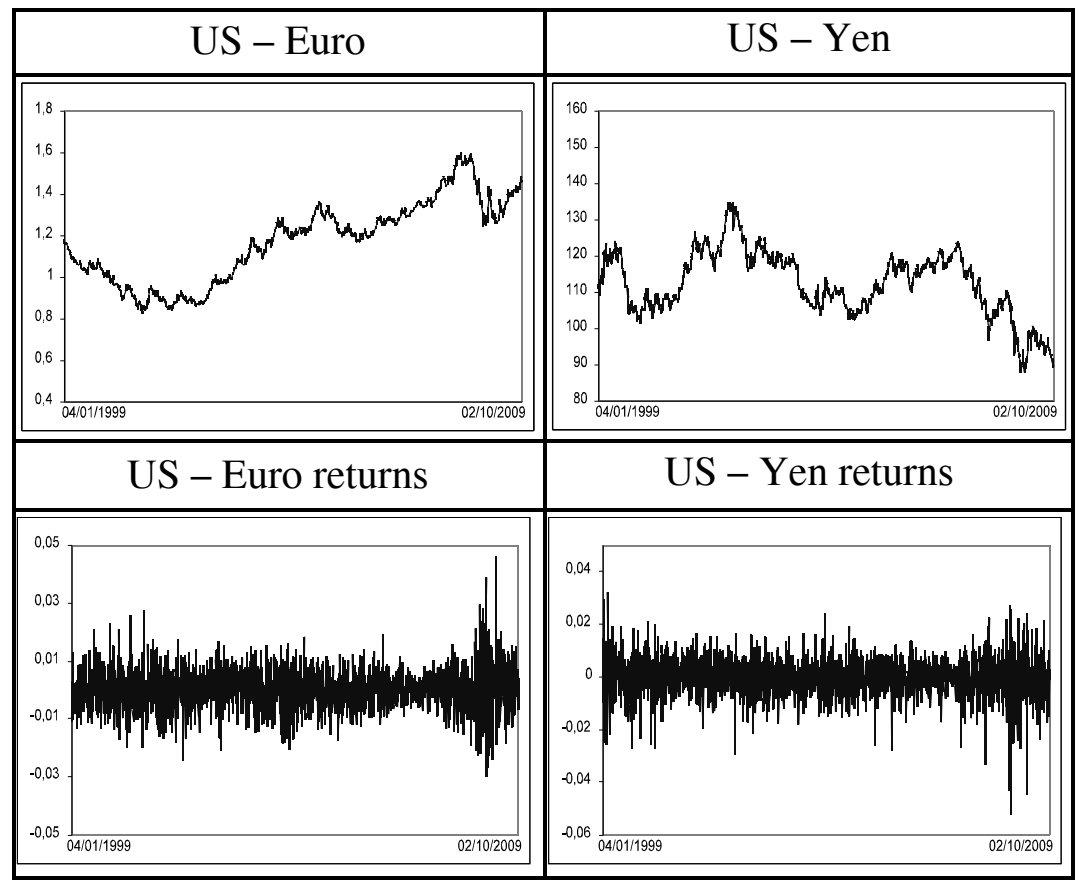

FIGURE 1.- Foreign exchange rate time series and their corresponding returns

where $x_{t}$ is assumed to be fractionally integrated as in equation (1). Thus, if $d=1$, the series follows a unit root process. ${ }^{3}$

Table 2 reports the estimates of $d$ in (6) and (1) for the three standard cases of no regressors (i.e., $\alpha=\beta=0$ a priori in equation (6)), an intercept ( $\alpha$ unknown, and $\beta=0$ a priori), and an intercept with a linear time trend ( $\alpha$ and $\beta$ unknown), under the assumption that the error term $\left(u_{t}\right.$ in (1)) follows a white noise process, an AR(1), and the exponential spectral model of Bloomfield (1973) in turn. The latter is a non-parametric specification that produces autocorrelations decaying exponentially as in the AR case and allows to approximate ARMA structures with a small number of parameters. ${ }^{4}$

3. The presence of outliers (towards the two ends of the sample) was also taken into account by applying standard procedures in this context. Their presence was found not to alter the main conclusions reported in the paper.

4. See Gil-Alana (2004) for the use of fractional integration with Bloomfield disturbances in the context of Robinson's (1994) tests. 
TABLE 2. Estimates of $d$ in the log exchange rates series

\begin{tabular}{|c|c|c|c|}
\hline \multicolumn{4}{|c|}{ i) White noise disturbances } \\
\hline & No regressors & An intercept & A time trend \\
\hline Log of US-Euro & 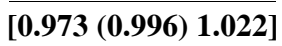 & 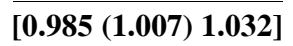 & $\overline{[0.985(1.007)} 1.032]$ \\
\hline Log of US-Yen & {$\left[\begin{array}{lll}0.974 & (0.997) & 1.023\end{array}\right]$} & [0.946 (0.969) 0.994$]$ & {$[0.946(0.969) 0.994]$} \\
\hline \multicolumn{4}{|c|}{ ii) $\mathrm{AR}(1)$ disturbances } \\
\hline & No regressors & An intercept & A time trend \\
\hline Log of US-Euro & [0.927 (0.970) 1.017] & {$\left[\begin{array}{lll}0.971 & (1.005) & 1.043]\end{array}\right.$} & [0.971 (1.005) 1.043] \\
\hline Log of US-Yen & {$\left[\begin{array}{lll}0.980 & (0.999) & 1.018\end{array}\right]$} & {$[0.940(0.976) 1.018]$} & {$[0.940(0.976) 1.018]$} \\
\hline \multicolumn{4}{|c|}{ iii) Bloomfield disturbances } \\
\hline & No regressors & An intercept & A time trend \\
\hline US-Euro & 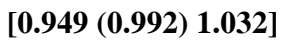 & $\overline{[0.971(1.008)} 1.041]$ & $\overline{[0.971(1.008)} 1.041]$ \\
\hline Log of US-Yen & {$\left[\begin{array}{lll}0.953 & (0.991) & 1.032\end{array}\right]$} & 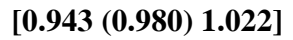 & [0.943 (0.980) 1.022] \\
\hline
\end{tabular}

Note: In brackets the $95 \%$ confidence interval for the values of $d$. In parentheses, the Whittle estimates. We report in bold the cases where the unit root hypothesis cannot be rejected.

Table 2 displays the 95\% confidence intervals formed by the non-rejection values of $d$, using Robinson's (1994) parametric approach in the frequency domain. It is also presented (in parentheses inside the square brackets) the Whittle estimates of $d$ (Dahlhaus, 1989) in each case. It can be seen that the intervals almost always include the unit root, the only exceptions being the US dollar-Yen rate with an intercept and with a linear trend, where the estimated value of $d$ is slightly below 1. In all other cases, the estimated $d$ is around 1, hence supporting the unit root model and justifying the use of returns in the remainder of the paper.

In what follows the paper focuses on the variance of the return series and examines the squared and absolute returns, which are used as proxies for volatility. These two measures have been widely employed in the financial literature to measure volatility. ${ }^{5}$ Plots of these series are displayed in figure 2 .

Figure 3 shows the first 1,000 sample autocorrelation values for the absolute and squared returns of the two series. It can be seen that the

5. Absolute returns were employed among others by Ding et al. (1993), Granger and Ding (1996), Bollerslev and Wright (2000), Gil-Alana (2005), Cavalcante and Assaf (2004), Sibbertsen (2004) and Cotter (2005), whereas squared returns were used in Lobato and Savin (1998), Gil-Alana (2003), Cavalcante and Assaf (2004) and Cotter (2005). 


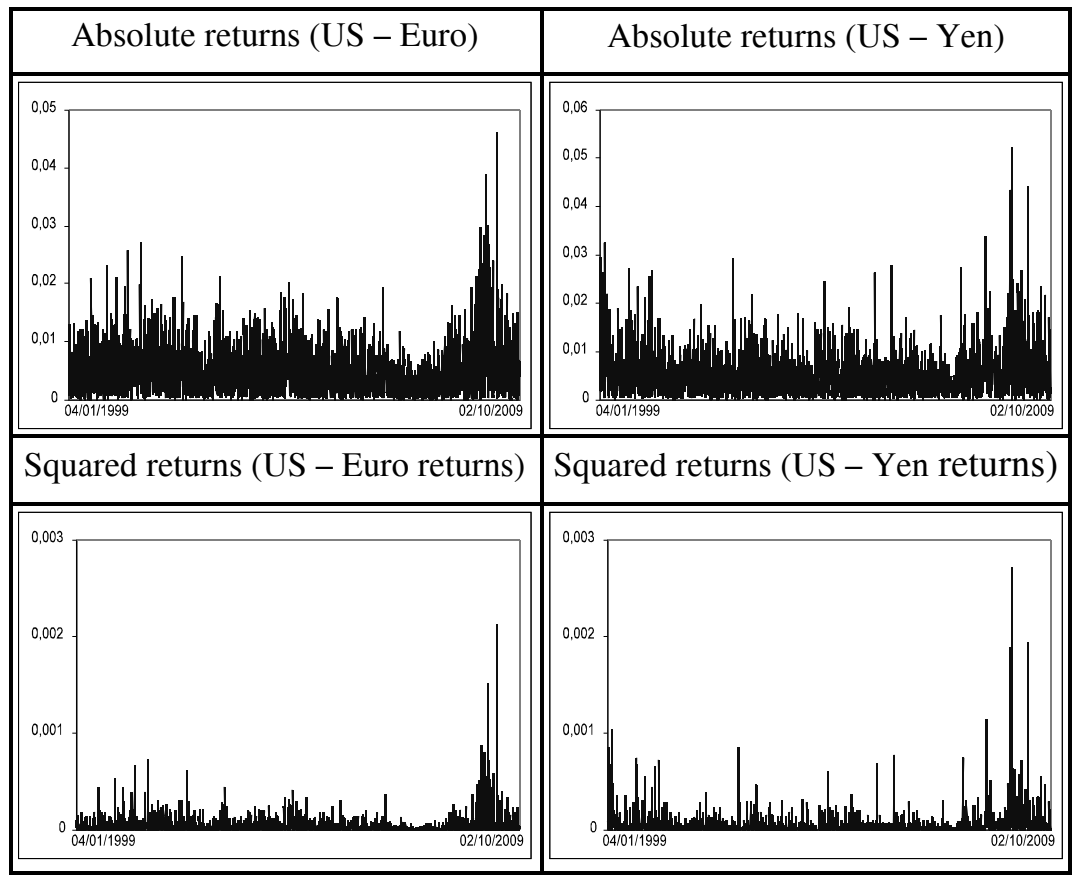

FIGURE 2.- Absolute and squared returns series

Note: The returns were obtained as the first differences of the logged transformed series.

four series display some degree of dependence with these values decaying very slowly, which may be consistent with fractionally integrated processes of the form given by equation (1). Moreover, there is some type of cyclical structure (especially for the Euro returns) which may imply that models of the form given by (2) or even (5) may also be plausible for these series. The periodograms, displayed in figure 4, have the highest values at the smallest frequencies, which is again an indication of possible $\mathrm{I}(d)$ behaviour with $d>0$, though this may be obscuring other peaks at non-zero frequencies.

First the results based on model 1 are presented, which is the one that displays long memory exclusively at the long-run or zero frequency, that is,

$$
y_{t}=\alpha+\beta t+x_{t} ; \quad(1-L)^{d} x_{t}=u_{t}, \quad t=1,2, \ldots,
$$

and, similarly to the results presented in table 2 , the three cases of no 


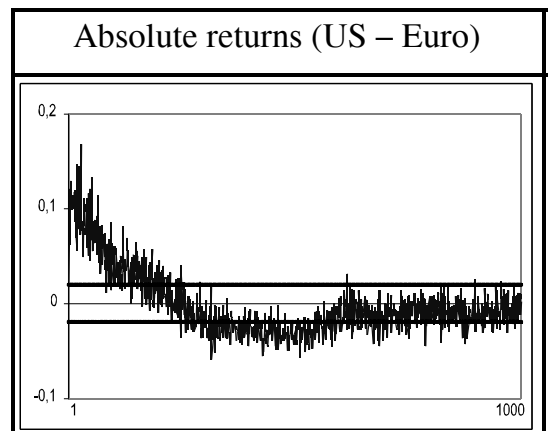

Absolute returns (US - Yen)

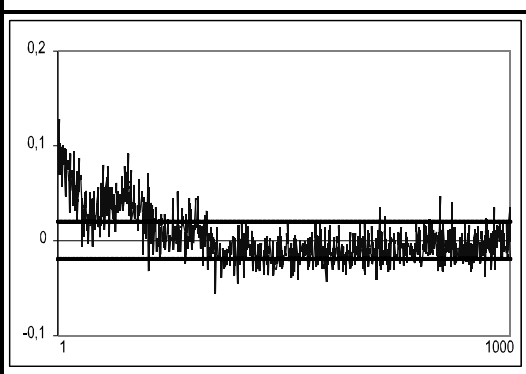

Squared returns (US - Euro returns)

Squared returns (US - Yen returns)
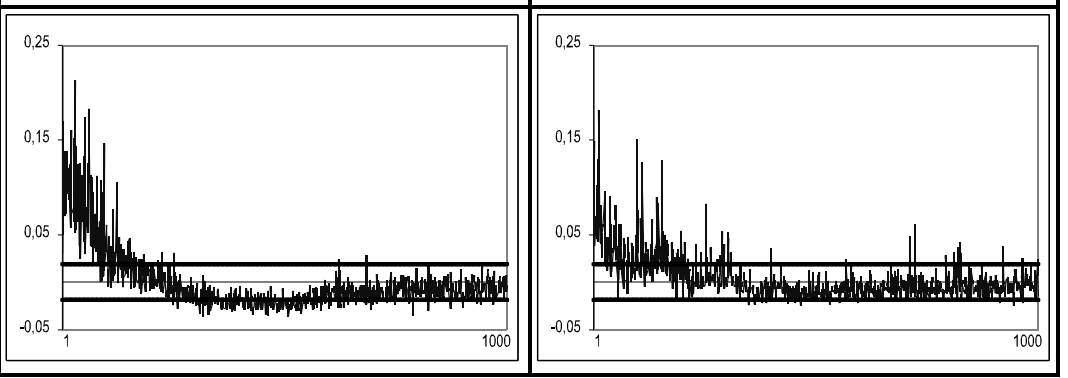

FIGURE 3.- Correlogram of the absolute and squared returns series

Note: The large sample standard error under the null hypothesis of no autocorrelation is $1 / \sqrt{ } \mathrm{T}$.

regressors, an intercept, and an intercept with a linear trend are reported, assuming that the disturbances follow a white noise, an $\mathrm{AR}(1)$ and a Bloomfield-type process in turn. ${ }^{6}$ The results are displayed in tables 3 and 4 for the absolute and squared returns respectively.

Starting with the absolute returns (in table 3), the estimated values of $d$ are in all cases strictly positive and smaller than 0.5 , i.e. inside the stationary region, though with some degree of long-memory behaviour. When not allowing for autocorrelation the estimated value of $d$ is around 0.10 for the US dollar-Euro rate, and is slightly higher for the US dollar-Yen one. If autocorrelation is allowed, in the form of either an AR process or of the Bloomfield model, the values of $d$ are higher and close to 0.2 in the two series. Very similar results are obtained in table 4 for the squared returns, with values close to 0.1 with uncorrelated errors and close to 0.2 with weak autocorrelation. Finally,

6. When using higher AR orders very similar results were obtained. 


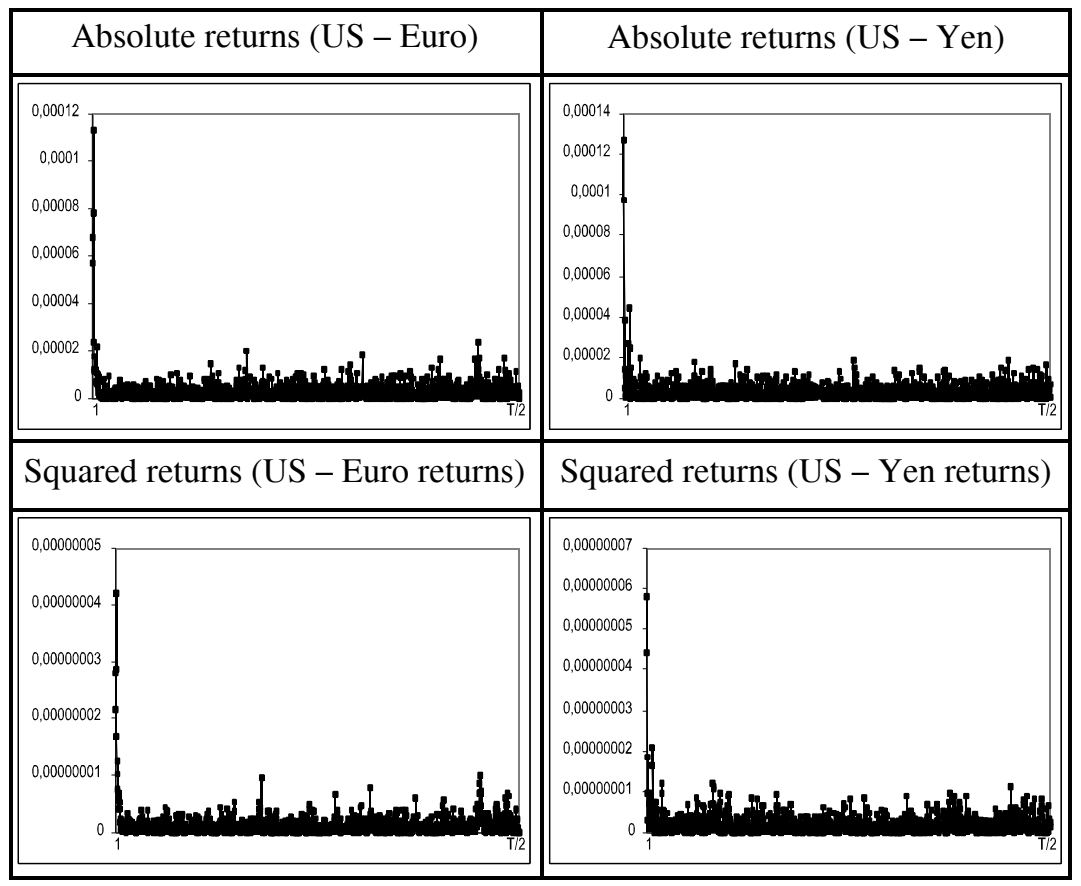

FIGURE 4.- Periodograms of the absolute and squared returns series

Note: The periodograms were computed based on the discrete Fourier frequencies $\lambda_{j}=2 \pi j / T$.

regarding the deterministic terms (not reported), the time trend coefficients were found to be insignificant in all cases, while the intercept was statistically significant at the $5 \%$ level, implying that the model including an intercept is the one that should be selected in all cases.

Because of the differences in the results depending on how the error term is specified, a semi-parametric method (Robinson, 1995) is also applied, in which the disturbances $u_{t}$ are simply assumed to be $\mathrm{I}(0)$ with no functional form required for them. This method is based on a "local" Whittle estimate in the frequency domain; it considers a band of frequencies that degenerates to zero, and the estimate of $d$ is implicitly defined by:

$$
\hat{d}=\arg \min _{d}\left(\log \overline{C(d)}-2 d \frac{1}{m} \sum_{j=1}^{m} \log \lambda_{j}\right),
$$


TABLE 3. Estimates of $d$ in model (M1) using the absolute returns

\begin{tabular}{|c|c|c|c|}
\hline \multicolumn{4}{|c|}{ i) White noise disturbances } \\
\hline & No regressors & An intercept & A time trend \\
\hline US-Euro & $\overline{[0.090(0.103) 0.118]}$ & $\overline{[0.086(0.098) 0.112]}$ & $\overline{[0.086(0.098)} 0.112]$ \\
\hline US-Yen & {$[0.113(0.130) 0.148]$} & [0.101 (0.116) 0.133$]$ & {$[0.100(0.115) 0.132]$} \\
\hline \multicolumn{4}{|c|}{ ii) $\mathrm{AR}(1)$ disturbances } \\
\hline & No regressors & An intercept & A time trend \\
\hline US-Euro & $\overline{[0.181(0.201) 0.224]}$ & $\overline{[0.170(0.188) 0.209]}$ & $\overline{[0.170(0.188) 0.209]}$ \\
\hline US-Yen & {$[0.186(0.212) 0.241]$} & {$[0.162(0.185) 0.212]$} & {$[0.160(0.184) 0.212]$} \\
\hline \multicolumn{4}{|c|}{ iii) Bloomfield disturbances } \\
\hline & No regressors & An intercept & A time trend \\
\hline Log of US-Euro & $\overline{[0.204(0.230)} 0.259]$ & $\overline{[0.189(0.209) 0.236]}$ & $\overline{[0.189(0.209) 0.236]}$ \\
\hline Log of US-Yen & {$[0.198(0.228) 0.259]$} & {$[0.169(0.196) 0.226]$} & {$[0.168(0.196) 0.226]$} \\
\hline
\end{tabular}

$$
\text { for } d \in(-1 / 2,1 / 2) ; \overline{C(d)}=\frac{1}{m} \sum_{j=1}^{m} I\left(\lambda_{j}\right) \lambda_{j}^{2 d}, \quad \lambda_{j}=\frac{2 \pi j}{T}, \frac{m}{T} \rightarrow 0,
$$

where $\mathrm{m}$ is a bandwidth parameter. ${ }^{7}$

Figure 5 displays for each series the estimates of $d$ based on the above procedure using the whole range of parameters for the bandwidth (displayed on the horizontal axis) ${ }^{8}$, including the $95 \%$ confidence interval corresponding to the $\mathrm{I}(0)$ case. It is clear that the four series exhibit long-memory $(d>0)$ behaviour, consistently with the results based on the parametric approach outlined above and with other studies such as Granger and Ding (1996).

Next a cyclical long-memory model of the form given by equation (2) is considered. This is motivated by the periodograms of the series. ${ }^{9}$ Figure 6 displays the first 100 values of the periodogram for the Fourier frequencies $\lambda_{r}=2 \pi r / T,(r=T / s)$, for $r=1, \ldots, 100$. It is noteworthy that

7. Further refinements of this approach can be found in Velasco (1999), Phillips and Shimotsu (2004, 2005), Abadir et al., 2007, etc. Applying some of these methods we obtain almost identical results to those reported here.

8. The choice of the bandwidth is crucial since it affects the trade-off between bias and variance; specifically, the asymptotic variance and the bias of this estimator are decreasing and increasing with $m$ respectively.

9. Note that the periodogram is an asymptotic unbiased (though not consistent) estimate of the spectral density function. 
TABLE 4. Estimates of $d$ in model (M1) using the squared returns

\begin{tabular}{|c|c|c|c|}
\hline \multicolumn{4}{|c|}{ i) White noise disturbances } \\
\hline & No regressors & An intercept & A time trend \\
\hline US-Euro & [0.092(0.105) 0.118] & [0.093(0.106) 0.120$]$ & [0.091 (0.104) 0.120] \\
\hline US-Yen & [0.010(0.116) 0.135] & [0.097(0.114) 0.132] & [0.095 (0.112) 0.131$]$ \\
\hline \multicolumn{4}{|c|}{ ii) $\mathrm{AR}(1)$ disturbances } \\
\hline & No regressors & An intercept & A time trend \\
\hline US-Euro & {$[0.190(0.210) 0.236]$} & $\overline{[0.190(0.212)} 0.237]$ & {$[0.188(0.211) 0.235]$} \\
\hline US-Yen & [0.163(0.191) 0.224] & {$[0.158(0.186) 0.218]$} & [0.156 (0.184) 0.217] \\
\hline \multicolumn{4}{|c|}{ iii) Bloomfield disturbances } \\
\hline & No regressors & An intercept & A time trend \\
\hline US-Euro & {$[0.201(0.228) 0.351]$} & [0.201 (0.228) 0.352$]$ & {$[0.200(0.227) 0.356]$} \\
\hline US-Yen & [0.163(0.193) 0.235] & {$[0.160(0.189) 0.221]$} & {$[0.159(0.188) 0.221]$} \\
\hline
\end{tabular}

for the US Dollar-Euro case the highest value of the periodogram does not occur at the smallest frequency $(r=1)$ but instead at $r=4$, which should correspond to cycles with a periodicity of $T / 4 \approx 677$ periods (days). By contrast, for the US Dollar-Yen case the highest value is found at the smallest frequency $r=1$, followed by $r=19(T / 19 \approx 142$ periods). Therefore, model 2 is specified as:

$$
y_{t}=\alpha+x_{t} ; \quad\left(1-2 \cos w_{r} L+L^{2}\right)^{d} x_{t}=u_{t}, \quad t=1,2, \ldots
$$

with $w_{r}=2 \pi / 677$ in case of the US Dollar-Euro absolute and squared return series and $w_{r}=2 \pi / 142$ for the US Dollar-Yen values. The results using the above model are displayed in tables 5 and 6.

Two models, without regressors $(\alpha=0$ in (M2)) and with an intercept, are considered. Another version of Robinson's (1994) parametric tests is employed here, testing the null hypothesis $\mathrm{H}_{\mathrm{o}}: d=d_{\mathrm{o}}$, in (M2) for a range of values of $d_{\mathrm{o}}$ from 0 to 1 with 0.001 increments, and $s$ in $w_{r}$ equal to $600, \ldots, 700$ for the US Dollar-Euro case, and $s=$ $100, \ldots, 200$ for the US Dollar-Yen one. The model that produces the lowest statistic in Robinson (1994) for different values for $s$ and $d$ is selected. It is noteworthy that the estimated values of s are equal to 677 and 142 respectively for the two series, which correspond to some of the highest peaks in the periodograms displayed in figure 6 (specifically, the highest peak for the US dollar-Euro rate, and the second highest for the 

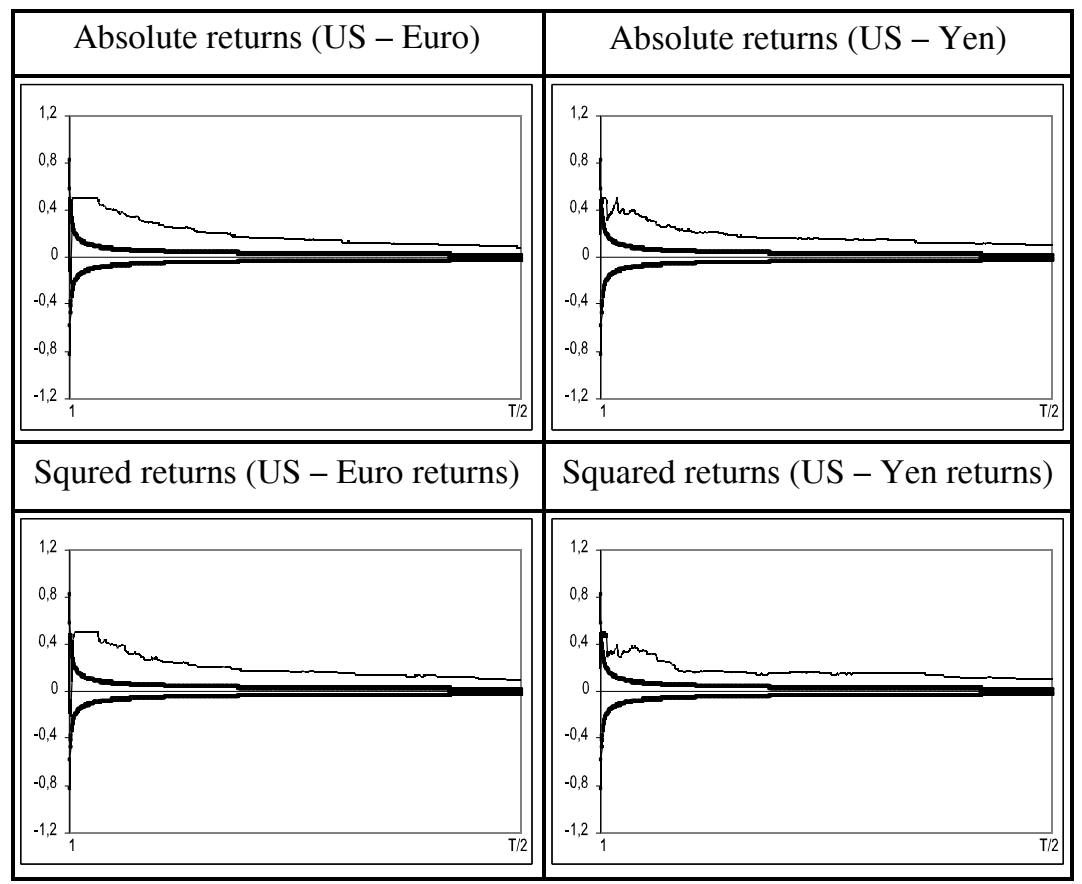

FIGURE 5.- Estimates of $d$ based on the Whittle semiparametric method (Robinson, 1995)

Note: The horizontal axis refers to the bandwidth parameter while the vertical one displays the estimates of $d$.

US dollar- Yen rate).

Starting with the absolute values of the returns (see table 5), it is found that the differencing parameter is strictly positive and significant, though very close to 0 in all cases: the estimated values of $d$ are 0.035 (US Dollar-Euro) and 0.049 (US Dollar-Yen) for the cases of white noise and Bloomfield disturbances, and 0.075 (US Dollar-Euro) and 0.080 (US Dollar-Yen) with AR(1) errors. For the squared returns (table 6) the values are again significant though slightly higher: 0.042 (US Dollar-Euro) and 0.050 (US Dollar-Yen) with uncorrelated and Bloomfield errors, and 0.092 (US Dollar-Euro) and 0.083 (US Dollar-Yen) with AR(1) disturbances. Once more, the intercepts are statistically significant in all cases. 


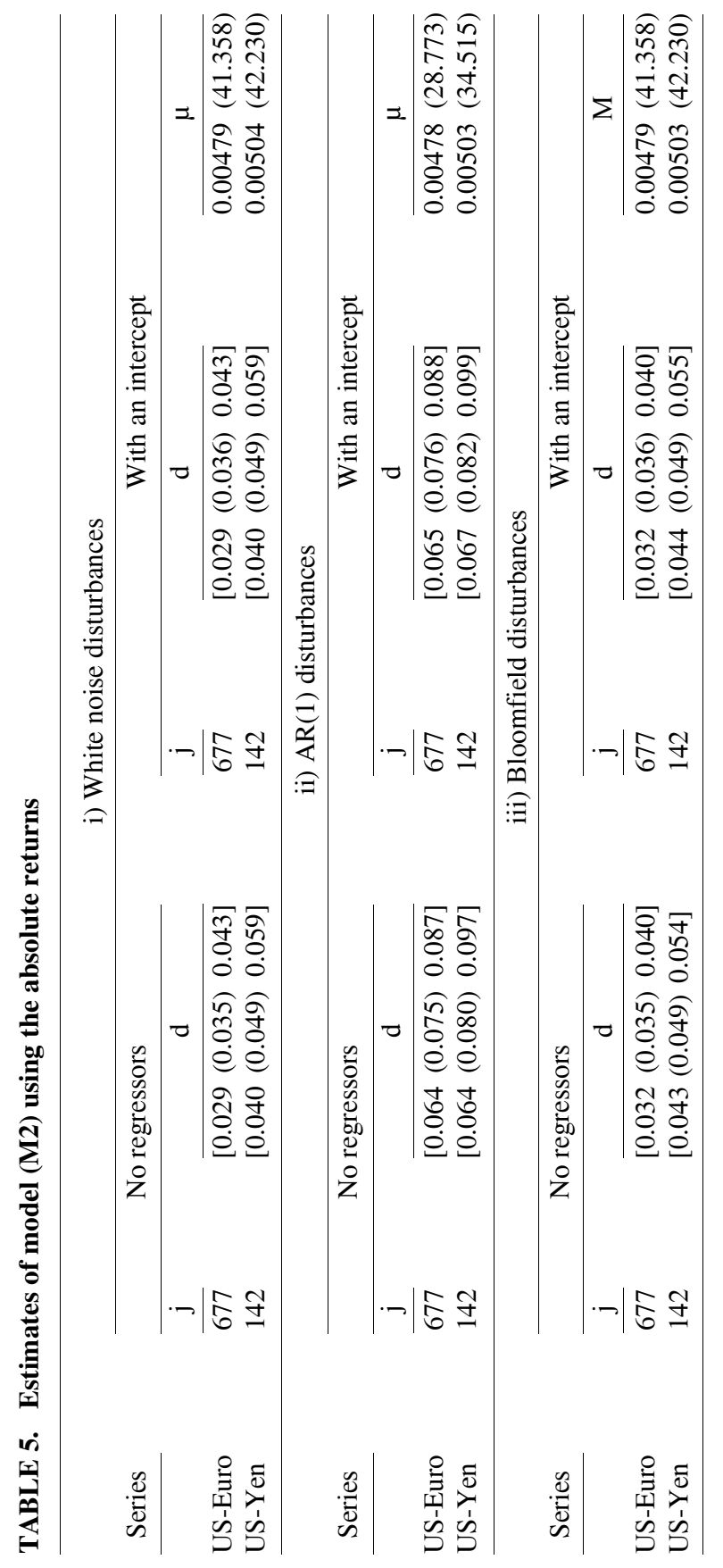




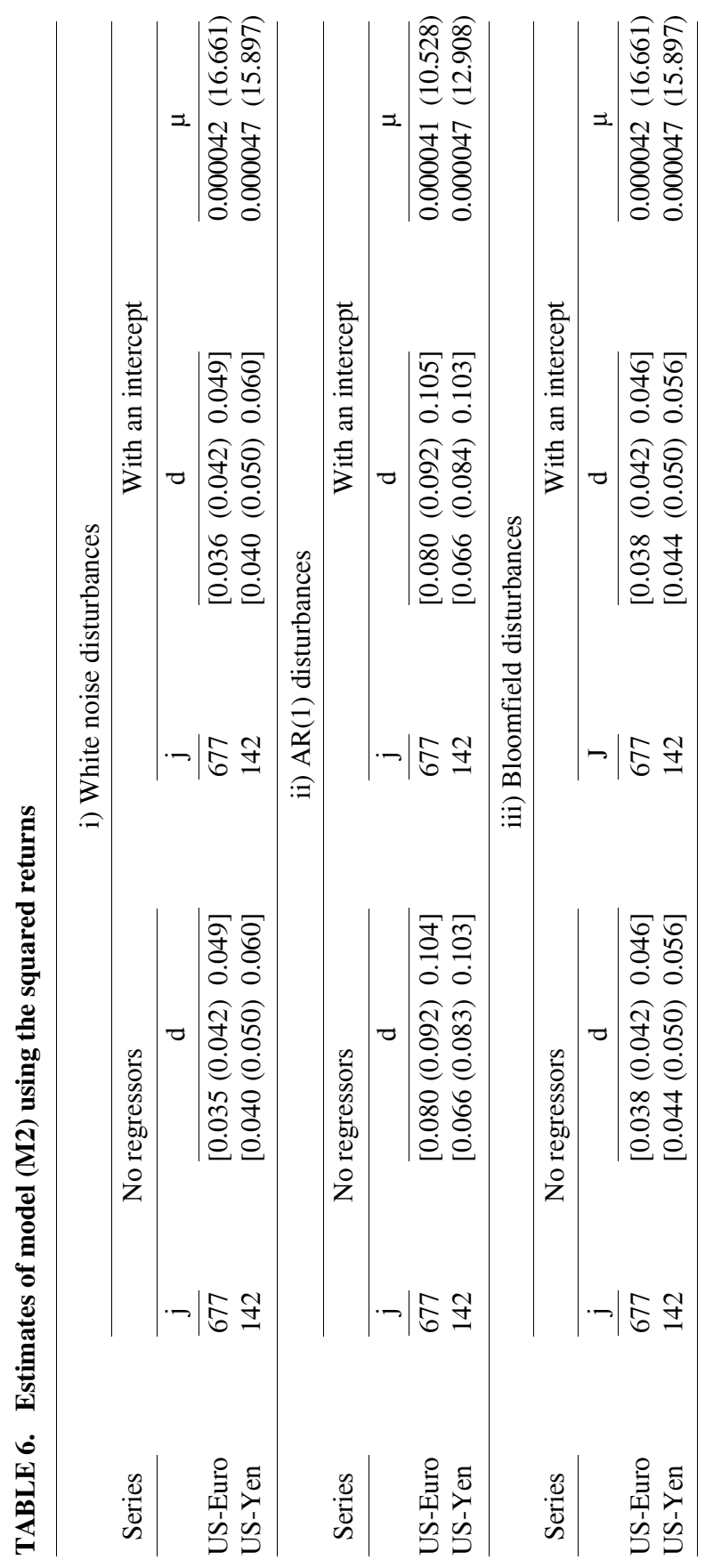




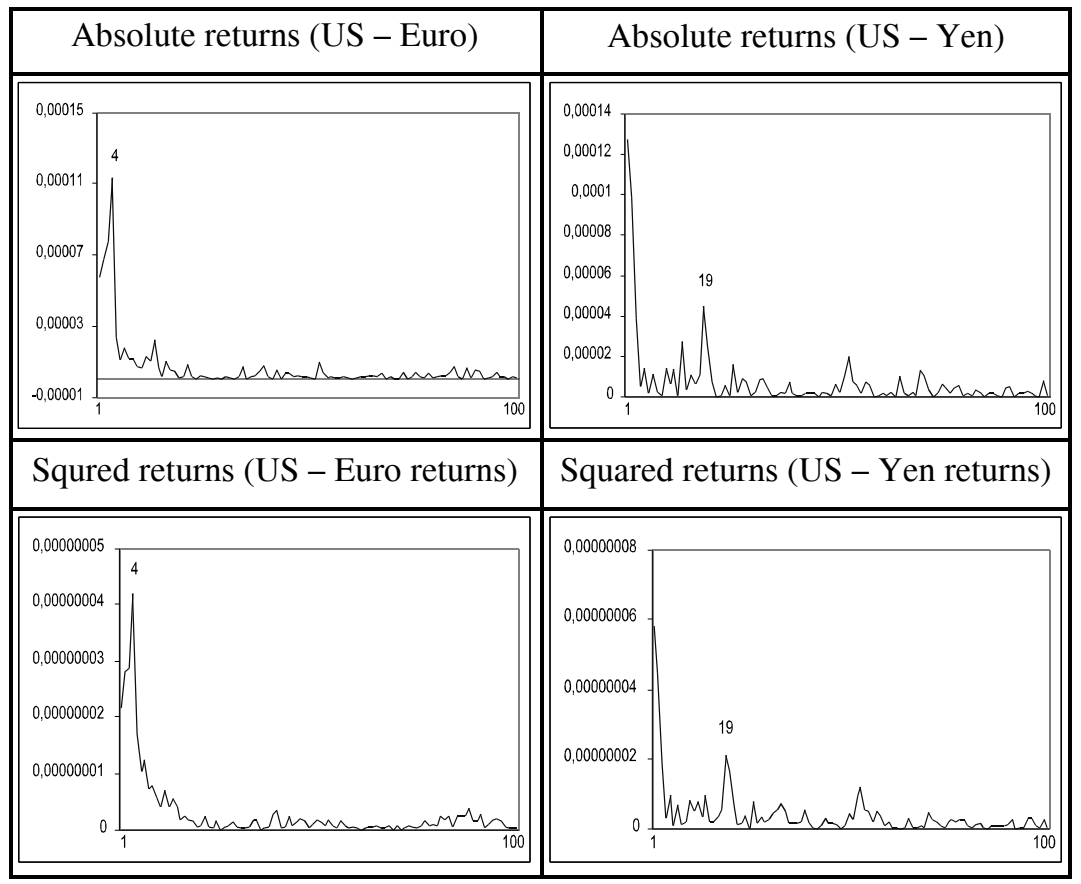

FIGURE 6.- First 100 values in the periodograms of the absolute and squared returns

Note: The periodograms were computed based on the discrete Fourier frequencies $\lambda_{j}=2 \pi j / T$.

Finally the case of a long-memory model that simultaneously takes into account the long-run and the cyclical structures is examined. Therefore, model 3 is specified as:

$$
y_{t}=\alpha+x_{t} ;(1-L)^{d_{1}}\left(1-2 \cos w_{r} L+L^{2}\right)^{d_{2}} x_{t}=u_{t}, t=1,2, \ldots,(\mathrm{M} 3)
$$

once more focusing on the cases of no regressors ( $\alpha=0$ in (M3)) and an intercept, for uncorrelated and correlated (AR and Bloomfield) errors.

The results based on (M3) are displayed in tables 7 and 8 . Interestingly, the selected models are once more those for the frequency $r$ that corresponds to $s=677$ for the US Dollar-Euro series case and to $s=142$ for the US Dollar-Yen one. Concerning the estimates of the fractional differencing parameters, for the US Dollar-Euro $d_{1}$ is not significantly different from zero, and the same holds for $d_{2}$ in the case 


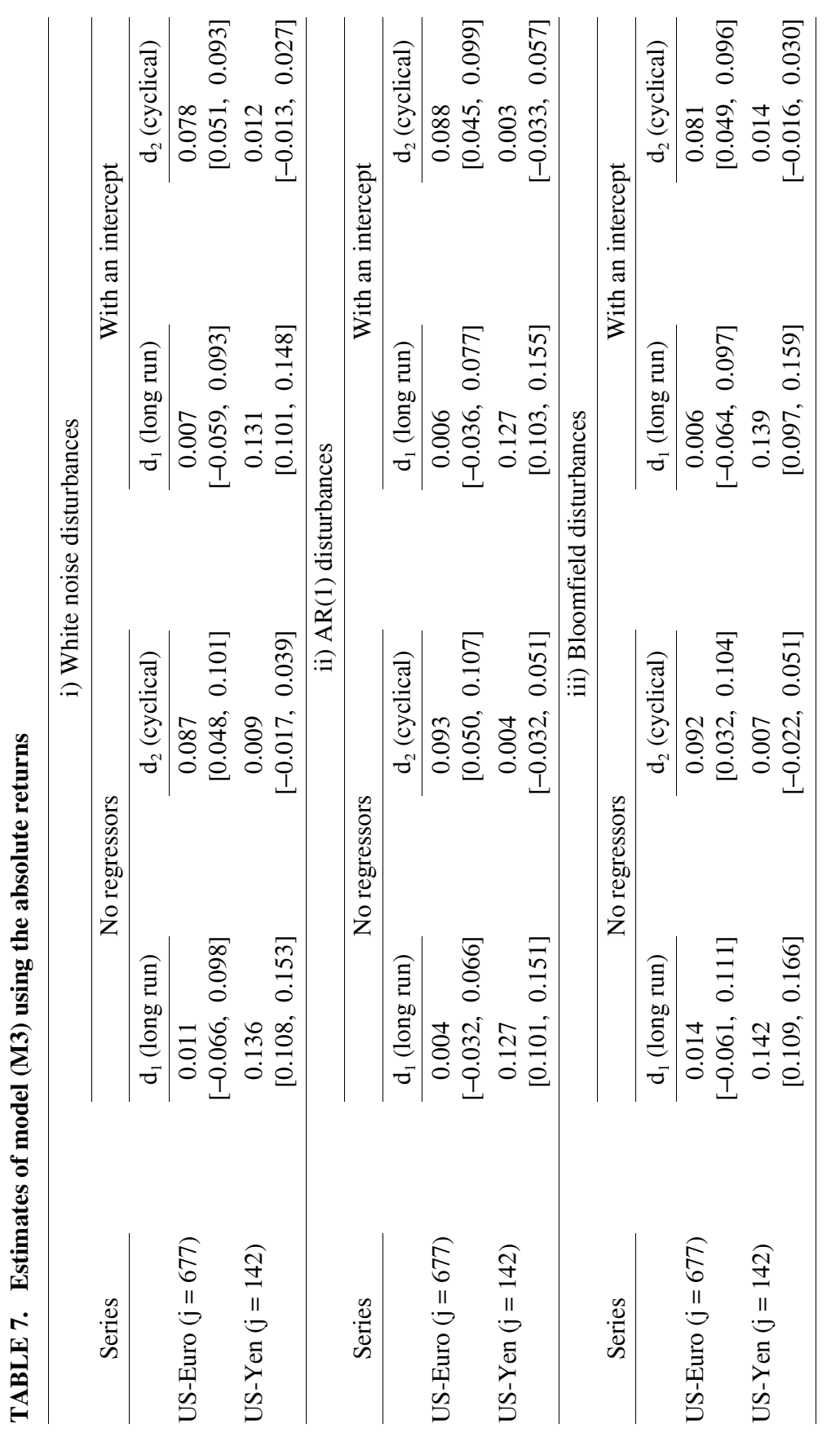




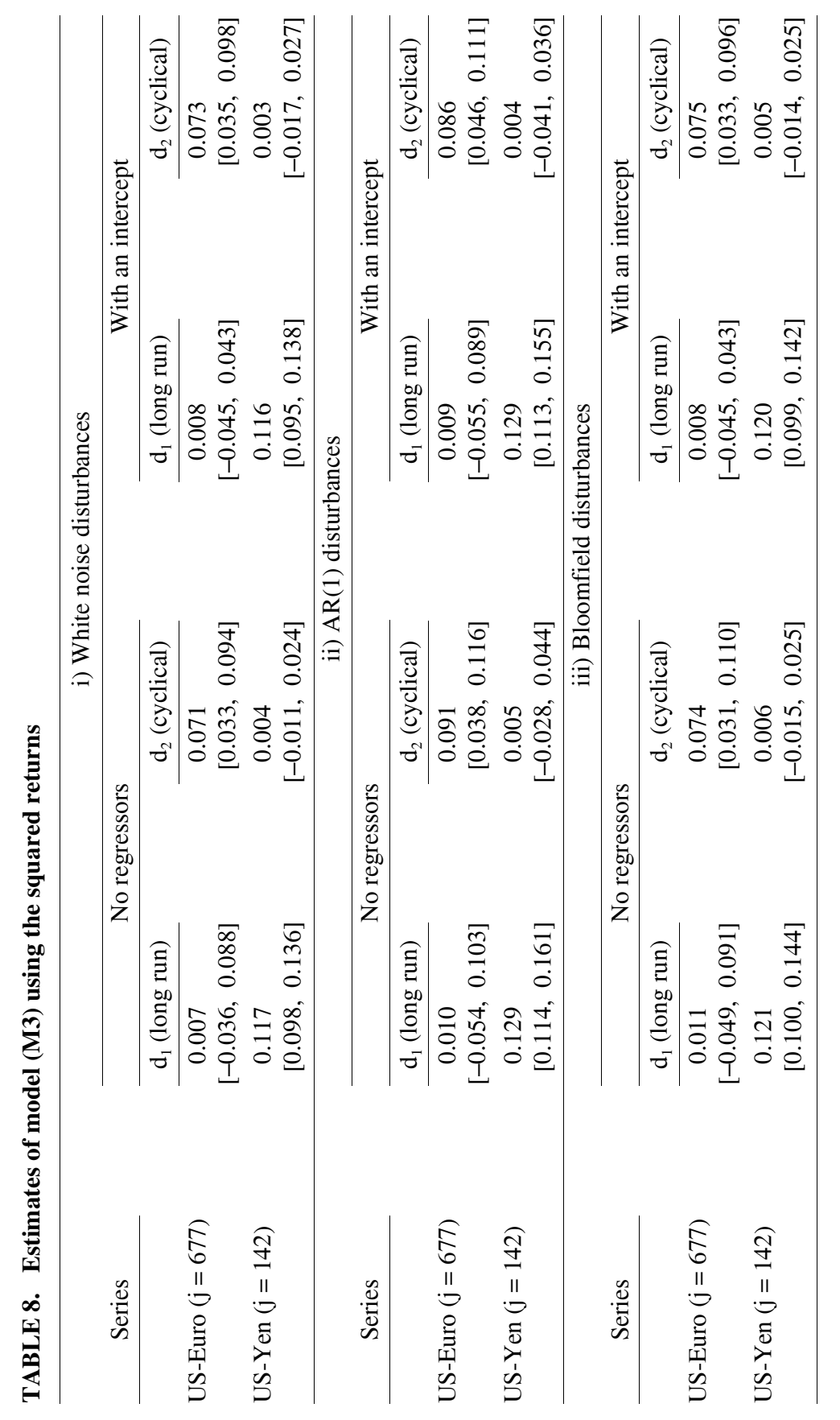


of the US Dollar-Yen. Therefore, model 2 and model 1 appear to be the most adequate ones for the US Dollar-Euro and the US Dollar-Yen cases respectively. We also perform LR tests to choose between models 1 and 3 for the US Dollar-Yen, and between models 2 and 3 for the US Dollar-Euro; these provide further evidence that model 2 (long-run cyclical dependence) is more appropriate for the US Dollar-Euro (absolute and squared) returns, and model 1 (standard I $(d)$ ) for the US Dollar-Yen values.

On the basis of this evidence as well as the t-values for the deterministic terms the models below are selected. For the US dollar-Euro series:

$$
y_{t}=0.00479+x_{t} ; \quad\left(1-2 \cos w_{4} L+L^{2}\right)^{0.036} x_{t}=u_{t}, \quad t=1,2, \ldots, \text { (7) }
$$

in the case of the absolute returns, and

$$
y_{t}=0.000042+x_{t} ; \quad\left(1-2 \cos w_{4} L+L^{2}\right)^{0.042} x_{t}=u_{t}, \quad t=1,2, \ldots,
$$

for the squared returns.

However, for the US dollar-Yen values, a model with long memory only at the zero frequency seems to be more adequate, namely

$$
\begin{gathered}
y_{t}=0.00526+x_{t} ; \quad(1-L)^{0.185} x_{t}=u_{t} ; u_{t}=-0.144 u_{t-1}+\varepsilon_{t}, \\
t=1,2, \ldots,
\end{gathered}
$$

for the absolute returns, and

$$
\begin{gathered}
y_{t}=0.000051+x_{t} ; \quad(1-L)^{0.186} x_{t}=u_{t} ; u_{t}=-0.139 u_{t-1}+\varepsilon_{t}, \\
t=1,2, \ldots,
\end{gathered}
$$

for the squared values.

Clearly, both volatility series are characterised by long memory, but in case of the US dollar - Yen rate this affects the long run structure of the process, while in the case of the US dollar - Euro there is an underlying cyclical pattern. 


\section{Stability tests and structural breaks}

In this section it is examined whether the results reported in Section III are stable over the sample period or instead subject to structural change. For this purpose once more the versions of Robinson's (1994) tests employed in Section III are performed, using the specifications described above, starting with a sample of 1,500 observations and then adding recursively five observations each time till the end of the sample (with 2,710 observations). Figure 7 displayes the estimated values of $d$ for the absolute return series, for the Euro case (the upper plot) and for the Japanese Yen (in the lower part of the figure) respectively. In the former case, a model of a similar form to the one given by equation (8) is employed, i.e., using cyclical fractional integration,

$$
y_{t}=\mu+x_{t} ; \quad\left(1-2 \cos w_{r} L+L^{2}\right)^{d} x_{t}=u_{t}, \quad t=1,2, \ldots
$$

while in the latter case (Japanese yen absolute returns) we use a model similar to equation (10), i.e., based on a standard $\mathrm{I}(d)$ model,

$$
y_{t}=\mu+x_{t} ; \quad(1-L)^{d} x_{t}=u_{t} ; \quad u_{t}=\rho u_{t-1}+\varepsilon_{t}, \quad t=1,2, \ldots
$$

As can be seen, for the US dollar-Euro absolute returns the estimated value of the (cyclical) fractional differencing parameter remains close to 0 (and statistically insignificant) for each subsample until the one ending at the observation 2035, which corresponds to February 5, 2007. If observations after that date are included, the estimate is above 0.010 , becoming significantly different from 0 for each subsample till the end of the sample period, with another increase at observation 2460 (October 6, 2008). Focusing now on the US dollar-Yen case, the estimate of the fractional differencing parameter, $d$, is relatively stable till observation 2320 (March 20, 2008), with values around 0.12; there is then an increase (with values close to 0.15 ) till observation 2460 (October 6, 2008), and another one ( $d$ about 0.20) until the end of the sample. Similar results (not reported for reasons of space) were obtained for the squared returns.

Because of the instability in the estimated fractional differencing parameter (see figure 7) in what follows three different subsamples for each series are considered. These are: for the US dollar-Euro, [January 4, 1999 - February 5, 2007]; [February 6, 2007 - October 6, 2008] and 

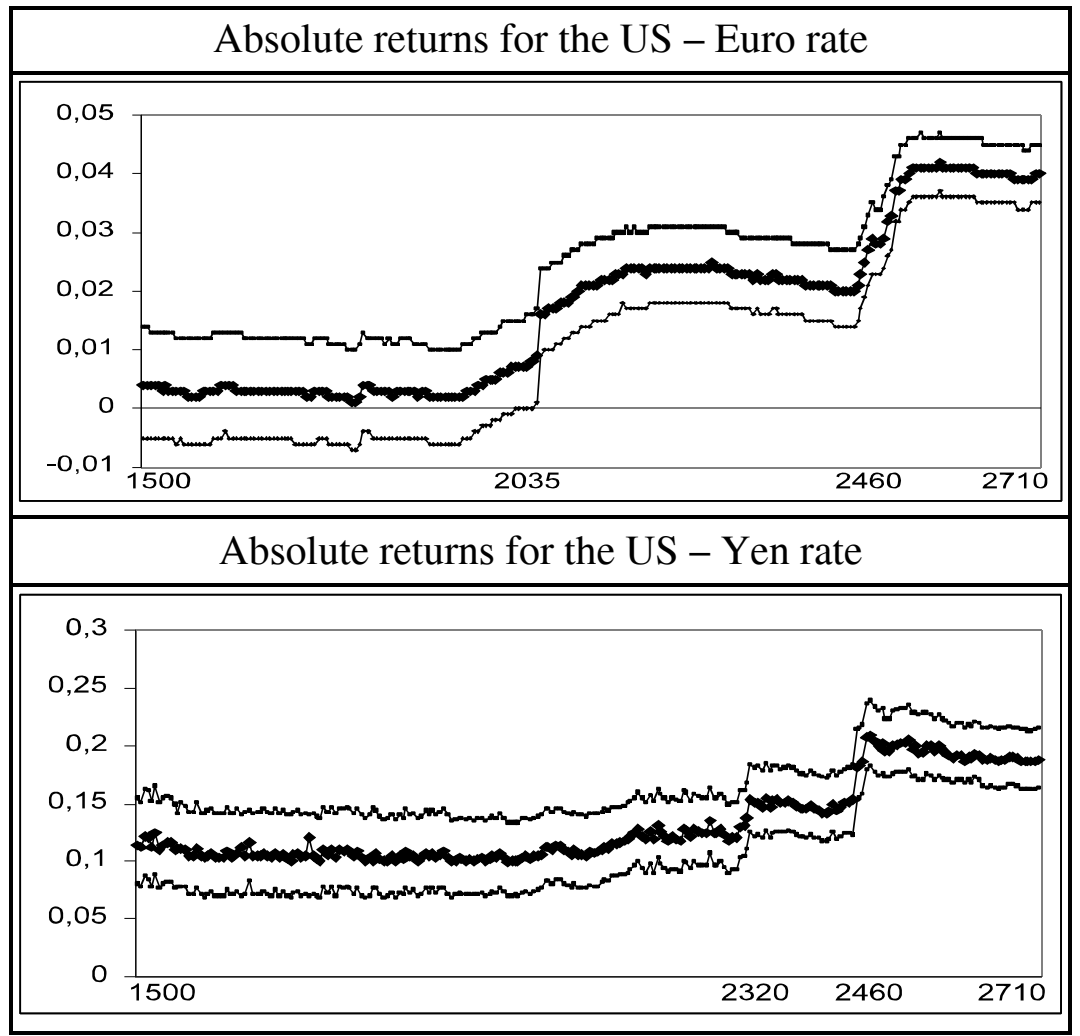

FIGURE 7.- Recursive estimates of the fractional differencing parameter

Note: The thin lines refer to the $95 \%$ confidence interval.

[October 7, 2008 - October 2, 2009], and for the US dollar-Yen [January 4, 1999 - March 20, 2008], [March 21, 2008 - October 6, 2008] and [October 7, 2008 - October 2, 2009].

Table 9 displays the estimates of the long-run and the cyclical fractional differencing parameters using model 1 and model 2 for each subsample and each series. The upper and lower half of the table concern the absolute and squared returns respectively. Considering the subsamples separately it can be seen that some of the estimates are statistically significant, especially in the case of model 1 (with long memory at the long-run or zero frequency). Also, the estimated value of $d$ for model 1 is higher in the second subsample and lower in the third 


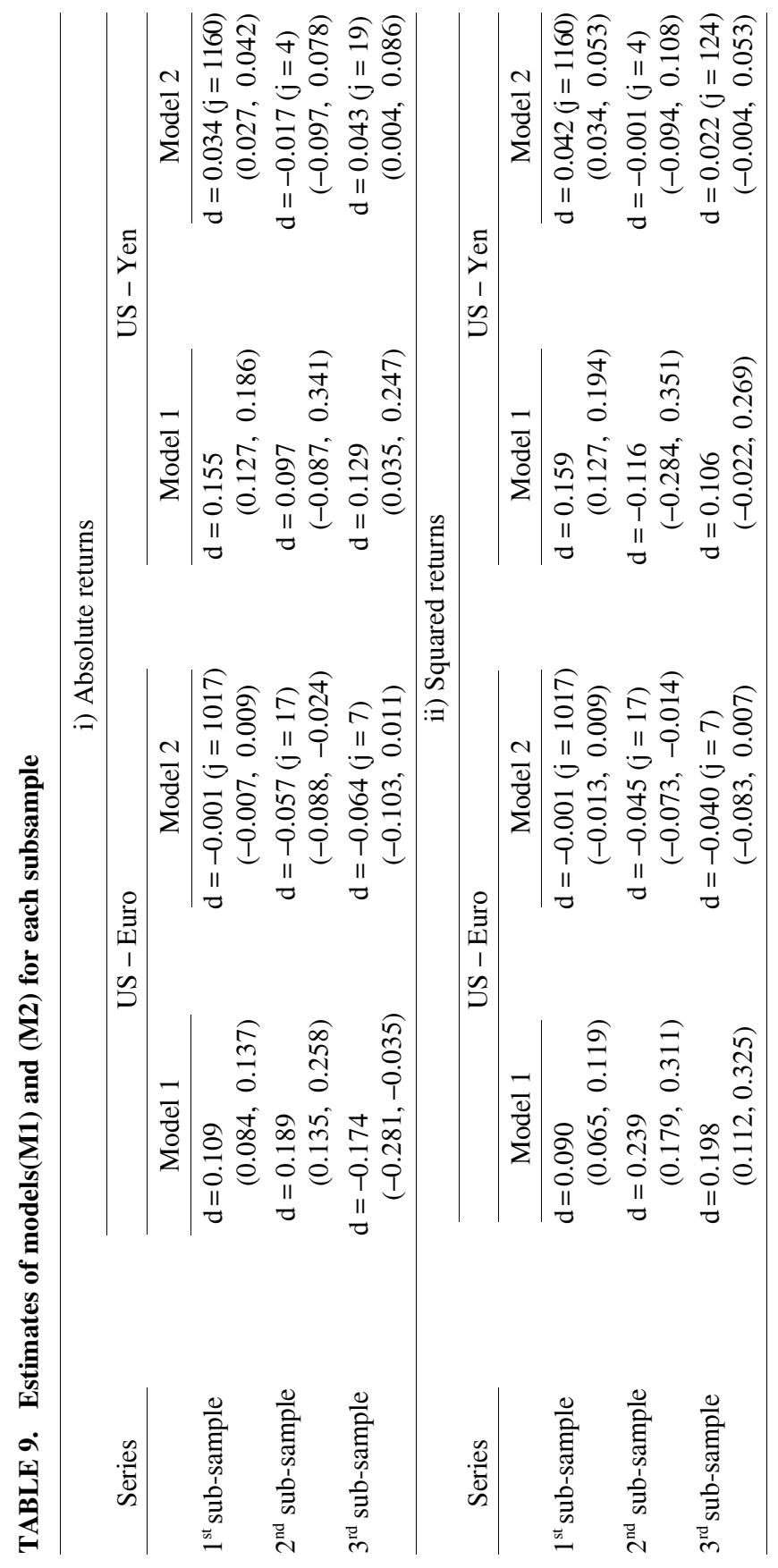


subsample for the US dollar-Euro rate (for both absolute and squared returns), whilst for the US dollar-Yen rate there is a decrease in the second subsample and an increase in the third one (see table 9).

The above approach assumes that the break dates are known. In what follows, it is used instead a procedure developed by Gil-Alana (2008) that endogenously determines the number of breaks and the break dates along with the parameters in the model. In what follows, this approach is briefly described which is based on minimizing the residuals sum of squares across the different subsamples. Gil-Alana (2008) considers the following model,

$$
y_{t}=\beta_{i}^{T} z_{t}+x_{t} ; \quad(1-L)^{d_{i}} x_{t}=u_{t}, \quad t=1, \ldots, T_{b}^{i}, \quad i=1, \ldots n b,
$$

where $\mathrm{nb}$ is the number of breaks (i.e., $n b=0,1,2,3$ ), $y_{t}$ is the observed time series, the $\beta_{i}$ 's are the coefficients corresponding to the deterministic terms; the $d_{i}$ 's are the orders of integration for each subsample, and the $T_{b}{ }_{b}$, s correspond to the dates of the unknown breaks. The method is based on minimizing the residuals sum of squares for a grid of values of the fractional differencing parameters and the time breaks.

The results using this approach indicate that there are two potential breaks for the US -Euro absolute returns, which coincide with the values obtained in figure 7 (i.e., February, 2007, and October, 2008). However, for the US - Yen absolute returns, only one break is detected, occurring in October 2008 (which is the second one of the two detected in figure 7). Evidence of a small degree of long memory $(d>0)$ is obtained across all the subsamples.

\section{Forecasting performance}

In this section the forecasting accuracy of the models presented in previous sections is examined. For this purpose, it is considered for each of the four series (i.e. the absolute and squared returns of the US dollar exchange rates against the Euro and the Japanese Yen) the three models that have been presented in Section 3, i.e., model 1 (M1): fractional integration at the zero frequency; model 2 (M2): fractional cyclical integration; and model 3 (M3): fractional integration at both the zero and the cyclical frequencies. 


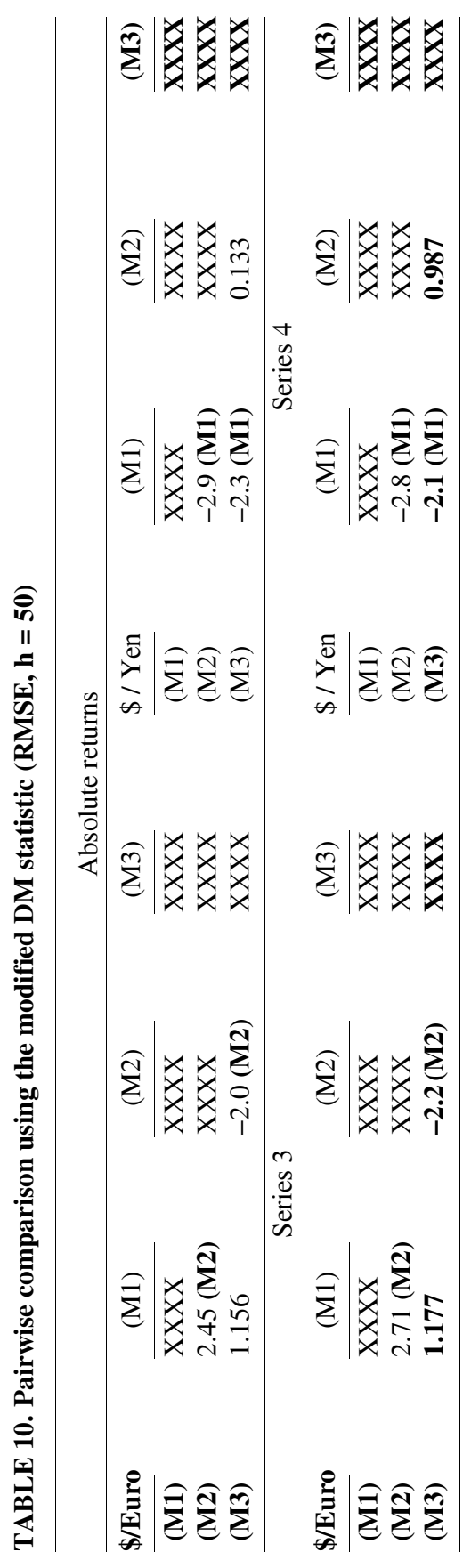




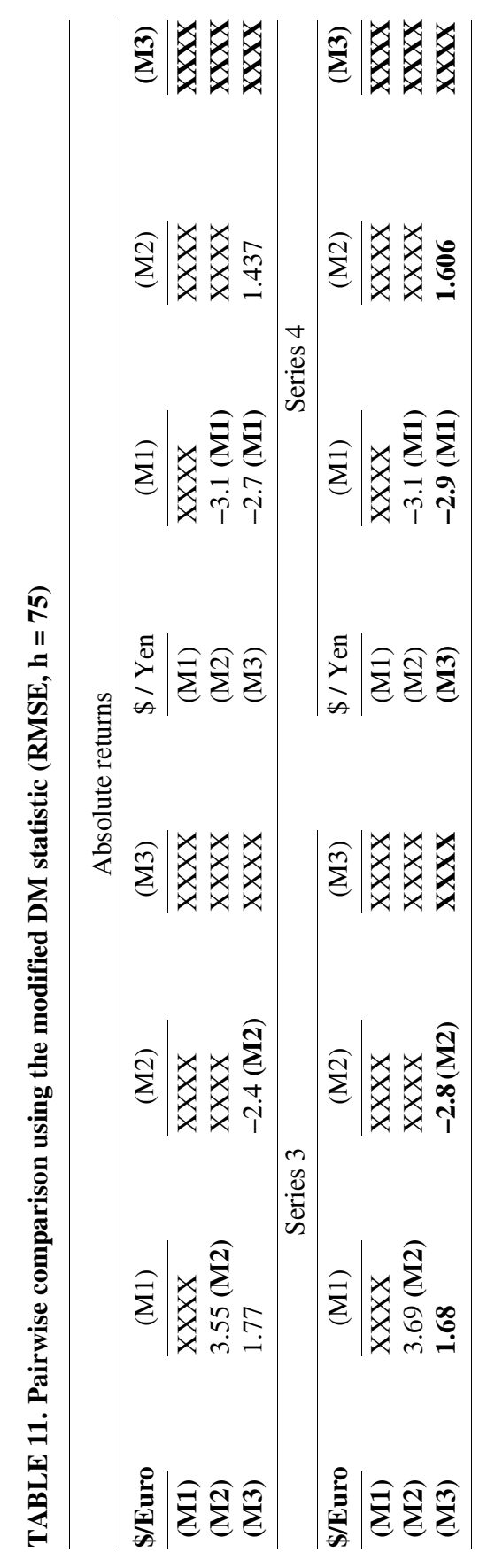




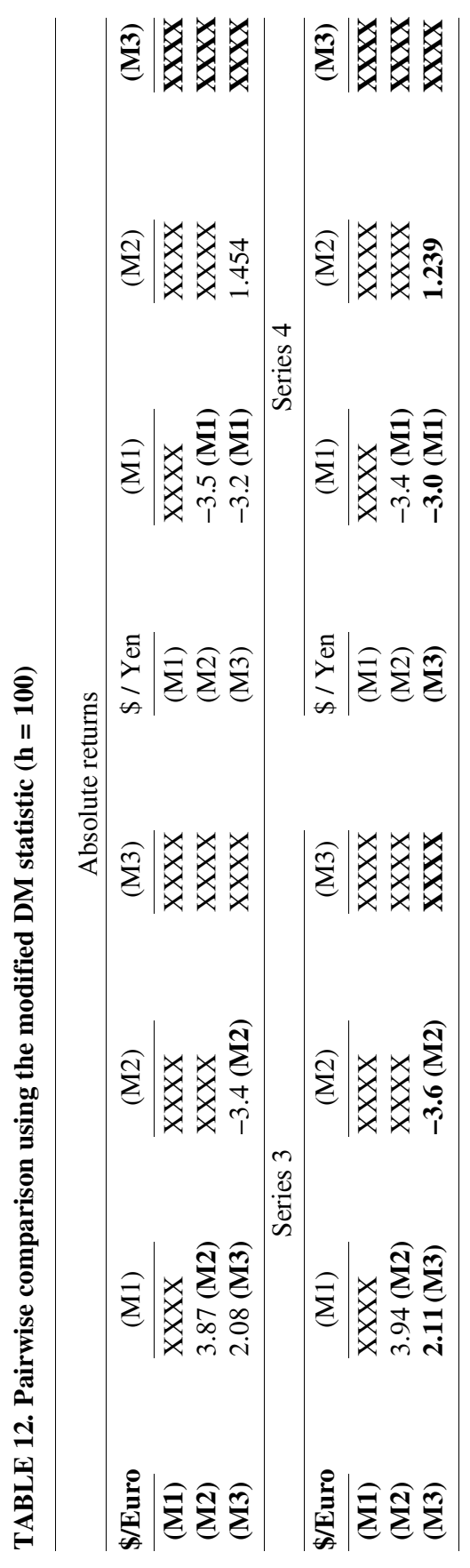


An in-sample forecasting experiment is performed to establish which of the three models (M1, M2 or M3) performs best for each series. First, the root mean squared errors are computed for the last 100 observations in the sample. Then, the modified Diebold and Mariano (M-DM, 1995) statistic as suggested by Harvey, Leybourne and Newbold (1997) is conducted. ${ }^{10}$

Using the M-DM test statistic, the relative forecast performance of the different models is performed by making pairwise comparisons. The root mean squared errors is used in the computations. The results are displayed in tables 10,11 and 12 respectively for 50, 75 and 100-period ahead predictions.

For each prediction-horizon it is indicated in the tables in bold the rejections of the null hypothesis that the forecast performance of model (Mi) and model $(\mathrm{Mj})$ is equal in favour of the one-sided alternative that model (Mi)'s performance is superior at the $5 \%$ significance level. The results for the three time horizons are consistent with the conclusions based on the estimation results of Section III: model 2 (M2), i.e., the cyclical fractionally integrated one, seems to be the most adequate specification for the US dollar-Euro absolute and squared returns, while model 1 (M1), the standard I $(d)$ model, is the preferred one for the two US dollar/ Yen returns series.

\section{Conclusions}

This paper has applied long-memory methods to analyse the US dollar rate vis-à-vis the Euro and the Japanese Yen at a daily frequency, with particular attention being paid to volatility modelling and forecasting. Specifically, a more general fractional integration model compared with previous studies is estimated, allowing for dependence not only at the zero but also at other frequencies. The results show differences in the behaviour of the two series: a long-memory (Gegenbauer) process capturing the underlying cyclical structure and a standard $\mathrm{I}(d)$ model seem to be the most appropriate for the US dollar rate vis-à-vis the Euro and the Japanese Yen respectively. Consequently, mean reversion with hyperbolical decay occurs in both cases in response to exogenous

10. Harvey et al. (1997) and Clark and McCracken (2001) show that this modified test statistic performs better than the DM test statistic in finite samples, and also that the power of the test is improved when p-values are computed with a Student t-distribution. 
shocks to the volatility process, but in the former cyclicality is present. The in-sample forecasting analysis also indicates that the cyclical fractional model outperforms other models in case of the Euro return series, while a standard $\mathrm{I}(d)$ model outperforms other long memory models in the case of the Yen returns.

The analysis carried out in this paper can be extended to allow for non-linear structures and other procedures in the context of structural breaks as the one based on Markov-Switching models proposed by Tsay and Hardle (2009) could be applied. Work along these lines will be carried out in future papers.

Accepted by: Prof. P. Theodossiou, Editor-in-Chief, August 2011

\section{References}

Abadir, K.M.; Distaso, W.; and Giraitis, L. 2007. Nonstationarity-extended local Whittle estimation. Journal of Econometrics 141: 1353-1384.

Andel, J. 1986. Long memory time series models. Kybernetika 22: 105-123.

Andersen, T.G., and Bollerslev, T. 1997. Heterogeneous information arrivals and return volatility dynamics: uncovering the long run in high frequency returns. The Journal of Finance 52: 975-1005.

Andersen, T.G., and Bollerslev, T. 1998. Deutsche Mark-Dollar volatility: intraday activity patterns, macroeconomic announcements, and longer run dependencies. The Journal of Finance 53: 219-265.

Baillie, R.T.; Bollerslev, T.; and Mikkelsen, H.O. 1996. Fractionally integrated generalized autoregressive conditional heteroscedasticity. Journal of Econometrics 74: 3-30.

Baillie, R.T.; Cecen, A.A.; and Han, Y.W. 2000. High frequency Deutsche mark - US dollar return. FIGARCH representations and non-linearities. Multinational Finance Journal 4: 247-267.

Baum, C.F.; Barkoulas, J.; and Caglayan, M. 1999. Persistence in the international inflation rates. Southern Economic Journal 65: 900-913.

Bloomfield, P. 1973. An exponential model in the spectrum of a scalar time series, Biometrika 60: 217-226.

Bollerslev, T., and Wright, J.H. 2000. High frecuency data, frequecy domain inference and volatility forecasting, Review of Economics and Statistics 83: 596-602.

Booth, G.G.; Kaen, F.R.; and Koveos, P.E. 1982. R/S analysis of foreign exchange markets under two international monetary regimes. Journal of Monetary Economics 10: 407-415. 
Cavalcante, J., and Assaf, A. 2004. Long range dependence in the returns and volatility of the Brazilian stock market. European Review of Economics and Finance 3: 5-22.

Cheung, Y.W. 1993. Long memory in foreign exchange rates. Journal of Business and Economic Statistics 11: 93-101.

Cheung, Y.W., and Lai, K.S. 1994. Mean reversion in real exchange rates. Economics Letters 46: 251-256.

Chung, C.F. 1996a. A generalized fractionally integrated autoregressive moving-average process. Journal of Time Series Analysis 17: 111-140.

Chung, C.F. 1996b. Estimating a generalized long memory process, Journal of Econometrics 73: 237-259.

Cotter, J. 2005. Uncovering long memory in high frequency UK futures, European Journal of Finance 11: 325-337.

Crato, N., and Ray, B.K. 2000. Memory in returns and volatilities of future's contracts. Journal of Futures Markets 20: 525-543.

Dalla, V., and Hidalgo, J. 2005. A parametric bootstrap test for cycles. Journal of Econometrics 129: 219-261.

Dickey, D. A., and Fuller, W.A. 1979. Distribution of the estimators for autoregressive time series with a unit root. Journal of the American Statistical Association 74: 427-431.

Ding, Z.; Granger, C.W.J.; and Engle, R.F. 1993. A long memory property of stock markets and a new model. Journal of Empirical Finance 1: 83-106.

Elliot, G.; Rothenberg, T.; and Stock, J. 1996. Efficient tests for an autoregressive unit root. Econometrica 64: 813-836.

Fang, H.; Lai, K.S.; and Lai, M. 1994. Fractal structure in currency futures price dynamics. Journal of Futures Markets 14: 169-181.

Ferrara, L., and Guegan, D. 2001. Forecasting with k-factor Gegenbauer processes. Theory and Applications. Journal of Forecasting 20: 581-601.

Frankel, J. 1986. International capital mobility and crowding out in the U.S. economy: imperfect integration of financial markets or goods markets?. in R. Hafer (ed.), How Open is the U.S. Economy?, Lexington Books, Lexington.

Gil-Alana, L.A. 2003. Fractional integration in the volatility of asset returns. European Review of Economics and Finance 2: 41-52.

Gil-Alana, L.A. 2004. The use of the Bloomfield (1973) model as an approximation to ARMA processes in the context of fractional integration. Mathematical and Computer Modelling 39: 429-436.

Gil-Alana, L.A. 2005. Long memory in daily absolute and squared returns in the Spanish stock market. Advances in Investment Analysis and Portfolio Management 1: 198-217.

Gil-Alana, L.A. 2007. Testing the existence of multiple cycles in financial and economic time series. Annals of Economics and Finance 1: 1-20.

Gil-Alana, L.A. 2008. Fractional integration and structural breaks at unknown periods of time. Journal of Time Series Analysis 29: 163-185. 
Giraitis, L., and Leipus, R. 1995. A generalized fractionally differencing approach in long memory modeling: Lithuanian Mathematical Journal 35: 65-81.

Granger, C.W.J., and Ding, Z. 1996. Varieties of long memory models. Journal of Econometrics 73: 61-78.

Gray, H.L.; Yhang, N.; and Woodward, W.A. 1989. On generalized fractional processes, Journal of Time Series Analysis 10: 233-257.

Gray, H.L.; Yhang, N.; and Woodward, W.A. 1994. On generalized fractional processes. A correction. Journal of Time Series Analysis 15: 561-562.

Kihc, R. 2004. On the long memory properties of emerging capital markets. Evidence from Istambul exchange. Applied Financial Economics 14: 915-922.

Lobato, I.N., and Savin, N.E. 1998. Real and spurious long memory properties of stock market data. Journal of Business and Economic Statistics 16: 261-268.

Lothian, J.R., and Taylor, M.P. 1997. Real exchange rate behaviour. Journal of International Money and Finance 16: 6, 945-954.

Magnus, W.; Oberhettinger, F.; and Soni, R.P. 1966. Formulas and theorema for the special functions of mathematical physics. Springer, Berlin.

McLeod, A.I., and Hipel, K.W. 1978. Preservation of the rescaled adjusted range. A reassessment of the Jurst phenomenon. Water Resources Research 14: 491-507.

Morana, C., and Beltratti, A. 2004. Structural change and long range dependence in volatility of exchange rates, either, neither or both?. Journal of Empirical Finance 11: 629-658.

Ng, S., and Perron P. 2001. Lag selection and the construction of unit root tests with good size and power. Econometrica 69: 1519-1554.

Phillips, P. C. B., and Perron, P. 1988. Testing for a unit root in a time series regression. Biometrika 75:335-346.

Phillips, P.C.B., and Shimotsu, K. 2004. Local Whittle estimation in nonstationary and unit root cases. Annals of Statistics 32: 656-692.

Phillips, P.C.B., and K. Shimotsu, 2005. Exact local Whittle estimation of fractional integration. Annals of Statistics 33, 1890-1933.

Rainville, E.D. 1960. Special functions. MacMillan, New York.

Robinson, P.M. 1994. Efficient tests of nonstationary hypotheses. Journal of the American Statistical Association 89: 1420-1437.

Robinson, P.M. 1995. Gaussian semi-parametric estimation of long range dependence. Annals of Statistics 23: 1630-1661.

Sadek, N., and Khotanzad, A. 2004. K-factor Gegenbauer ARMA process for network traffic simulation. Computers and Communications 2: 963-968.

Sibbertsen, P. 2004. Long memory in volatilities of German stock returns. Empirical Economics 29: 477-488. 
Tsay, W., and Hardle, W. 2009. A generalized ARFIMA process with Markov-Switching fractional differencing parameter. Journal of Statistical Computation and Simulation 79: 731-745

Tse, Y.K. 1998. The conditional heteroskedasticity of the Yen-Dollar exchange rate. Journal of Applied Econometrics 13: 49-55.

Velasco, C., 1999. Gaussian semiparametric estimation of nonstationary time series. Journal of Time Series Analysis 20: 87-127.

Wang, C. 2004. Futures trading activity and predictable foreign exchange movements. Journal of Banking and Finance 28: 1023-1041. 